\title{
An Analysis of Previewing Reading Strategy in Business Texts: A Think Aloud Protocol Study
}

\author{
Wuriy Handayani ${ }^{1} \&$ Nunung Widijantie ${ }^{2}$ \\ ${ }^{1}$ English Laboratory, ABFI Perbanas Institute, Jakarta, Indonesia \\ ${ }^{2}$ English Laboratory, Politeknik AKA Bogor, Bogor 16154, Indonesia \\ Correspondence: Nunung Widijantie, English Laboratory, Politeknik AKA Bogor, Bogor 16154, Indonesia.
}

Received: December 28, 2020 Accepted: January 13, 2021 Online Published: February 4, 2021

doi:10.11114/ijecs.v4i1.5151

URL: https://doi.org/10.11114/ijecs.v4i1.5151

\begin{abstract}
Students who study business and economics might read business texts related to their major. Some students get problem in finding main ideas or detail information. Finding main idea is not an easy job for EFL students since they need to understand the context and learn a lot of business vocabularies. To make it easier, there is one technique in reading which is called previewing. The business texts are previewed by students by reading the tittle, discussing the topic, and answering questions. This paper seeks to identify the effects of having previewing strategies used by EFL students and strategies most used by students in finding main idea and supported detail information. The qualitative research aimed at analyzing of how previewing can help students to find main ideas and detail information. This research also tried to decide whether students answered the questions correctly after using previewing strategy. Think Aloud Protocol (TAP) and interview collecting data techniques are carried to identify students' strategies. TAP is data collecting technique that involves verbal thought. This methodology is used to determine what goes on students' head while they are reading, finding main ideas and answering detail questions from business text. The research participants consist of thirteen students of the seventh semester in the Accounting major at ABFI Perbanas Institute Jakarta, Indonesia. The result shows that the participants used four parts of strategies in reading business text: (1) strategies of finding main idea, (2) strategies of finding detail information (strategies to find the word refers to, strategies of synonym, strategies to find definition), (3) previewing strategies, and (4) accuracy and inaccuracy to answer questions from reading business texts. The strategy that is often used by students in finding main idea is taking from the first sentence in paragraph. The strategies that are frequently used by students in finding detail information are referring to subject in previous sentence, choosing the right word from the option provided, finding the answer from dictionary and mentioning the place and time directly.
\end{abstract}

Keywords: previewing, EFL students and think aloud protocol

\section{Introduction}

When people continue to higher degree of education, reading considers being important activity during their study. Reading perceives a written text in order to understand its contents. This can be done silently or orally (Richards and Richard, 2002; Lumbantobing et. al, 2020). They also mention three purposes of reading, namely: reading in order to understand, reading to find information, reading to compare information and reading to gain an emotional value or response. According to Dhillon et. al (2020), reading becomes very important in the education field, where students need to be exercised and trained in order to have a good reading skill. Reading is also central to a student's experiences at school and in everyday life. Thus, teaching students to read is a major task for reading teachers today. Sirait et. al (2020) states that in this modern era, reading skill becomes the main thing for humans because the developments in every aspect of life grow and develop very quickly. Reading can be done anywhere and anytime. Nowadays, we can read a lot of information easier by the books, internet, magazine, newspaper, etc.

Students in university require to have plenty time in reading. They have to read many books and journals. The main objective in reading is to understand the texts. The strategies to understand the texts can be done in three ways such as before reading, during reading and after reading (Richards and Richard, 2002). Before reading, students can predict the content by previewing and set the purpose of reading. During reading, students can understand the text and find the purpose of reading. After reading, students can summarize, evaluate or giving comments about the text.

There are some advantages of reading during study in university. First, students can improve information and 
knowledge. Second, they can understand the lesson in the class. Third, they can answer some problems that arise while they are studying. Finally, they can produce new ideas and important suggestions. Students who learn business or economics subject might read different business texts relate with their study. Reading many business texts will help them to get used to business text. Reading business text is also the best strategy to understand vocabularies relate with business. There are many business texts that we often find such as business letter, journal and business articles.

Some students find problems in reading business texts. It happens because they do not get used to read business articles. It also happens because they do not know the meaning of some business vocabularies; they have limited knowledge about it and they even do not understand it. Another difficulty in reading business text is finding the main idea of the text. If students cannot find the main idea in business reading text, students will get difficulty in finding the topic of their reading such as what mostly discussed and being talked about. For example in reading comprehension, students had to answer the question "What is the main idea of the first paragraph?" Students answered the question in very long sentences which did not give the clear idea of the topic. The following paragraph describes the situation.

Reading text: The fashion industry in Europe is facing its biggest crisis in recent history. Clothing retailers such as H\&M, Zara and C\&A could have empty shops at Christmas because Chinese imports are stuck in European ports. At the moment, millions of Chinese bras, sweaters, and T-shirts are sitting in-customs warehouses around Europe, following the introduction of import controls in June by the European Trade Commissioner, Peter Mandelson. (Cook et. al, 2009)

Question : "What is the main idea of the first paragraph?"

Student's answer: The fashion industry in Europe is facing its biggest crisis in recent history. Clothing retailers such as H\&M, Zara and C\&A could have empty shops at Christmas because Chinese imports are stuck in European ports.

As we can see in the example above, instead of answering question with a short answer "The fashion industry in Europe is facing its biggest crisis in recent history" student answered question with a long sentence that described not only the topic sentence but also the supporting sentence of the paragraph.

Identifying main idea of the passage can increase comprehending the text. Main ideas provide general thought and ideas of the writers. It delivers message of the writers that is often stated directly or implied. Then recognizing main idea leads to details information in reading. Detail information will make reader understand the topic. Sometimes, main idea states writer feelings; like or dislike about the topic. As we can see in the paragraph below, the reading text describes the change in cost accounting and managerial accounting systems.

Reading text: A recent survey of UK businesses asked the question. "What reasons do you have for employing migrant workers?" The answer was good news for EU citizens who want to come and work in the UK, and bad news for young British people looking for work. About 20 per cent of employers think that migrant workers are more productive and have a more positive attitude to work than British workers. In addition 25 per cent of businesses can't find British workers with the necessary skills, and almost 20 per cent can't find people with the right experience. One hotel manager said. "If I had to choose between a local person and an EU migrant, I would always choose the migrant worker. In my experience, they work harder and have better skills." (Cook et. al, 2009).

The reading text above describes directly the reasons of having migrant workers in UK. It leads to detail information that most of the company in UK prefers to have migrant workers because they are more productive than British workers. It also shows writer's feeling, the feeling of supporting and preferring migrant workers than British workers.

This present study attempts to identify kinds of previewing strategies used by students in finding main ideas and detail information in business text. As it is mentioned above, previewing strategy is strategy used by students before reading text and answering some questions from the text. This research also tries to decide whether students answered the questions correctly after using previewing strategy. Different from previous research, the writers would like to use different method to collect data. The method is Think-Aloud Protocol. The Think-Aloud Protocol is data collecting technique that involves verbal thought. This methodology is used to determine what goes on students' head while they are reading, finding main ideas and answering detail questions from business text. To confirm on the strategies that students often used in finding main ideas and detail information, students answered some interview questions like which one is easier: answering the questions directly from reading text or having some questions about the topic first and which part that you like best for previewing: thinking about the topic, predicting the topic, or examining vocabularies in context. 


\section{Literature Review}

\subsection{Reading Strategy}

Reading strategy is the specific way that the students take to understand the content of text. We need to discover strategies used by students in finding main idea and detail information. To find strategies used by students, the process and the product in reading need to be discussed. Process of reading according to Alderson (2000) is the interaction between a reader and the text. The process happens before reading the text and during reading the text. The reader is thinking about what he is going to read, how he relates to other things he has known or read, what it means to him and what he expects to come next. He is likely thinking and gathering his knowledge before reading and he relates his knowledge with the context during reading. While product of reading based on Alderson (2000) is the measurement of reading comprehension. How teachers or lecturers typically design tests of understanding of particular texts. Then examine the results of the tests. Gonzales (2017) focused on reading strategies applied and administered to Centro Colombo Americano. Those strategies are what, how and why. For example, students need to read the first line of the paragraph to get the main idea for strategy what. Then for strategy how, students have to make connection between the first sentence in the first paragraph and the first sentence of other paragraphs. Using strategy why, students must get the general idea about the topic and make predictions. Result showed that students often use summarizing, skimming and previewing strategies in reading. Moreover, students get confuse with the steps of reading strategies with grammar, listening and writing. Souhila (2013) searched for the effectiveness of reading strategies to improve EFL students' reading comprehension. The reading strategies used are prediction, skimming, scanning, inferring, guessing the meaning of new words and self-monitoring. Those strategies are assumed to help to access comprehension in reading. She distributed questionnaires and test reading comprehension to first year of university students. Data of questionnaires showed that strategies of reading are effective and helpful for EFL students. Students need to learn and practice some strategies in reading at early stages and teachers must help students to learn those strategies.

\subsection{Previewing}

Strategy before reading that often used by students is previewing. Fellag (2006) describes preview, or view in advance, the reading title and any subheadings (smaller titles within the reading) or art (photographs, drawing, etc.) that accompany the reading. In other words, previewing is to guess the content of the text through reading the title or subheadings. Add prior knowledge before reading by seeing pictures or photographs, knowing the meanings of some vocabularies used in the text and answer some questions related with the text. Prichard and Andrew (2016) used eye tracking technology to evaluate the previewing strategies of Japanese L2 readers of English. Participants were giving task to read the text and making summary about the text. The eye tracking data revealed that most participants did little or no previewing of the text. Besides that, the participants also lack of summarizing skills.

\subsection{Self Explanation Reading Strategy (SERT)}

Many researchers have attempted to investigate previewing strategy in reading. Tenaha, et al (2004) examined the effects of self-explanation reading strategy (SERT) training to comprehend science texts on high school students. Nine biology classes were randomly grouped into three classes namely: SERT, previewing and control. SERT participants were provided training on how to do self- explanation reading strategy. They had to make various reading strategies to build connection between the reader's knowledge and the text. Preview participants had to preview the text before they read it. And control participants were simply asked to read the text. After reading, they had to create various reading strategies that helped them to memorize the text. The study showed that SERT helps students comprehend science text.

\subsection{Tittle, Examine, Look, Look, and Setting (TELLS)}

William (2006) examined one of previewing strategy called TELLS. It stands for Tittle, Examine, Look, Look and Setting. TELLS gives prior knowledge before reading. Result showed the effects on reading comprehension levels, reading comprehension rates and words correct per minute on previewed and un-previewed. The effects on reading comprehension levels showed high increase in comprehension level on previewed passages. However, the study presented that these increases were not stable between students. On the other hand, the study also showed no increase in comprehension level on un-previewed passages. Besides that, TELLS reading strategy may develop students' oral reading fluency. Words read correct per minute on previewed passages; it had big impact on reading comprehension.

\section{Method}

This study is qualitative and quantitative research. According to Williams and Andrew (2002) qualitative research is to describe the quality of something in some enlightening way. Qualitative research can lead to conclusion about what is possible, what can happen, or what can happen at least sometimes; it does not allow conclusion about what is probable, general or universal. In other words, qualitative research is used to measure data in subjective way. The aim is to provide detail description and specific information of what probably happen in our research. On the other hand, 
quantitative research is to be able to say something about generality of a given phenomenon or feature, about how typical or widespread it is, how much of it there is, about regularities, tendencies, frequencies, distributions. So, quantitative research seeks to measure data in objective way. It measures things that need to count and to compare statistically.

Think-Aloud Protocol (TAP) is one of data collection techniques in which subjects verbalize their thought, while they are doing language task. If we want to know student's strategy and find out how student solve their problems, we need to know what they think. Students' thoughts and feelings are under investigation in this method. Those thoughts and feelings are then transcribed and recorded. Nunan (2009) mentioned that think aloud protocols is one of introspective and introspection methods. If we want to know what people do, we need to know what they think. Introspective research subjects talk about their thought process and or feeling. Introspection is the process of observing and reporting on one's own thoughts, feelings, motives, reasoning process and mental states, often with a view to determining the ways in which these processes and states shapes behavior.

Anderson (2006) defines Think-Aloud Protocol method as the method used to solve cognitive problem such as solving strategies used by someone. According to them, the first procedure in think aloud protocol is the act of submitting transcripts and similar written records to systematic examination. The second procedure is arriving to the problem solution that the systematic examination is interested in. Then he explains Think-Aloud Protocol as a main technique for assessing students' learning strategies. This technique involves asking students to express their thoughts or strategies while they do a language task or soon thereafter.

The research participants consisted of thirteen students of the seventh semester in the Accounting major at ABFI Perbanas Institute Jakarta, Indonesia. The researchers chose those thirteen students because those students passed English for accounting in the first semester and English for business in the third semester. They have practiced reading and done some exercises related to reading comprehension. In this case, they have already thought general reading strategies such as previewing, skimming and scanning in the first and third semesters. There are thirteen students who participated in this research, namely AS, DC, RF, NT, FN, DM, AM, RD, AD, AR, AC, AF and AS.

The instrument used in this study was two reading texts taken from Cook, Rolf, Mara Pedretti, and Helen Stephenson, Total Business 1 Student's Book (2009). There are ten questions given to thirteen students. Those questions include finding main ideas and detail questions. The questions can be seen in the following table.

Table 1. List of Questions

\begin{tabular}{ll}
\hline Number & Questions \\
\hline 1. & What is the main idea of the first paragraph? \\
2. & What does the word "they" in the second paragraph line 4 refer to? \\
3. & The word "purchased" in the first paragraph, has similar meaning with: a. borrow b. buy c. sell \\
4. & Where did Ray open his first restaurant? \\
5. & When did Ray open the restaurant in Jakarta? \\
6. & What is the main idea of the first paragraph? \\
7. & "Product differentiation" means the product is ------- \\
8. & The word "emphasize" in line 10 is closest in meaning to --------- in paragraph two \\
9. & What does the word "they" in line 16 refer to? \\
10. &
\end{tabular}

The procedure consists of three steps: preparation of the test, the test, and Think-Aloud procedures. For preparation of the test, an hour briefing was held in the class to socialize the test, encourage students' awareness, and to train them to think aloud while they were answering questions.

In doing the test students were doing it in pairs. One student did the test and other student recorded it using their handphone. There are four parts of instruction during the test. Students was previewing the text before reading using previewing strategy, reading the texts, answering the following questions and answering some interview questions to confirm the strategies they used. Before reading the text, students had to choose the previewing strategies that they wanted to use in their reading. They thought about the topic, predicted the content and examined vocabulary in context. During the test, students had to read the texts, answered some questions and verbalized their thought. There was no time limitation for this test; they had to answer the questions and verbalize their thinking. After the test, students had to answer some interview questions about previewing strategy. 
To uncover the effects of having previewing strategies used by students and strategies most used by students in finding main ideas and detail information, the recordings of students' verbal report were transcribed. After it was transcribed, the transcriptions were analyzed due to reveal strategies when students were answering questions. To determine the accuracy of the answers made by students, the writers checked the answer of the test. To confirm about the effect and strategies used by students, the writers analyzed the answers from interview questions, described the findings, made some interpretations, and drew the conclusion.

\section{Results}

The findings were divided into four parts: (1) strategies of finding main idea, (2) strategies of finding detail information, comprising strategies to find the word refers to, strategies of synonym, strategies to find definition, (3) previewing strategies, and (4) accuracy and inaccuracy to answer questions from reading texts.

There were two questions about main idea in which one of them was from the first reading text and another was from the second reading text. The question was about the main idea of the first paragraph. There were varied strategies used by students to find main idea. They used more than one strategy to find main idea.

\subsection{Strategies of Finding Main Idea}

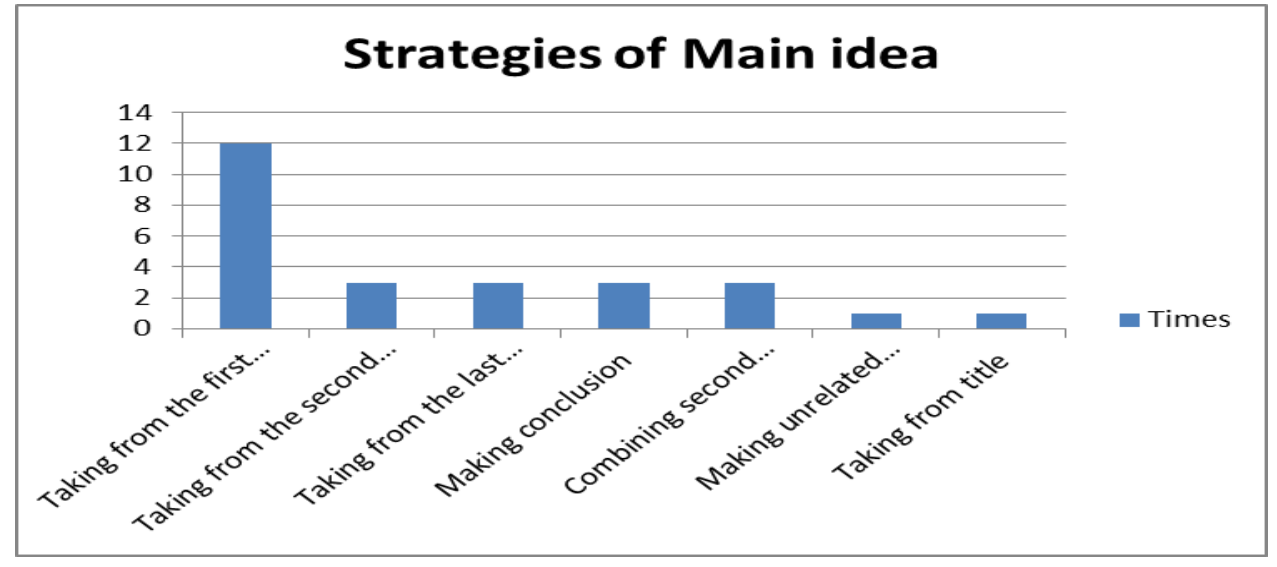

Figure 1. Strategies of Finding Main Idea

Figure 1 shows that the frequent strategies used by students in finding main ideas taken from the first, second, and the last sentences were 12,3, and 3 times respectively, while making conclusion and combining second sentence with first sentence, each of them was used 3 times. On the other hand, each strategy of making unrelated sentence and taking from the title was used once. In this case, the students mostly took the main idea from the first sentence.

\subsection{Strategies of Finding Detail Information}

Strategies used by students in finding detail information such as place, time and other information are called mentioning the answer directly and making conclusion. There were two questions about this. The questions were taken from reading text 1 number 4 and 5. Question number 4: "Where did Ray open his first restaurant?" Question number 5: "When did Ray open his restaurant in Jakarta? It was -------- ."

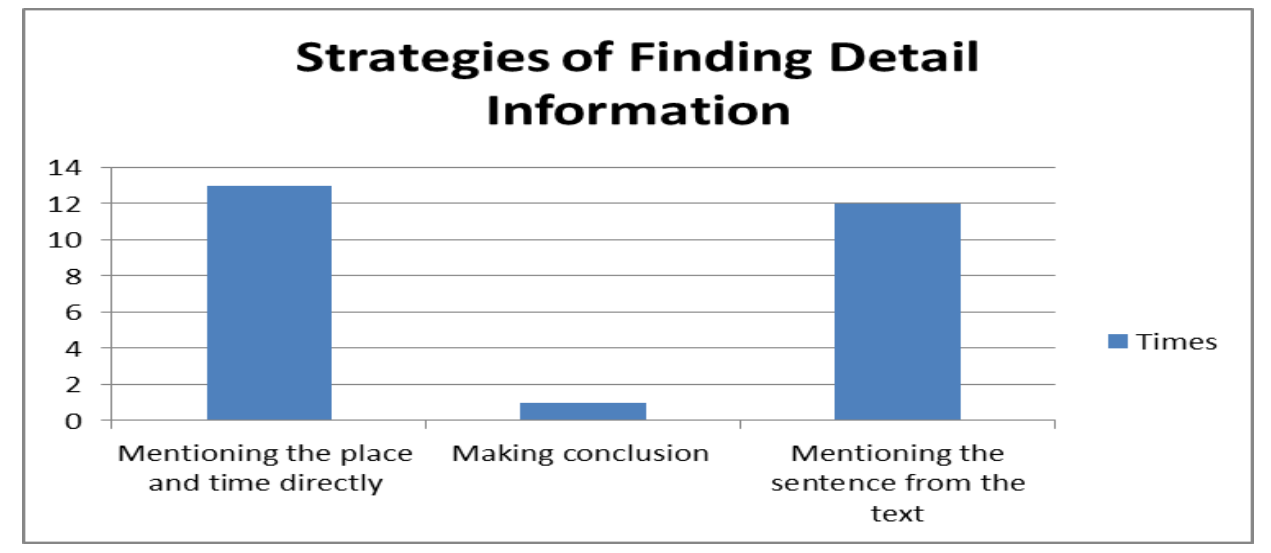

Figure 2. Strategies of Finding Detail Information

Figure 2 shows that in finding detail information, students used strategy of mentioning the place and time directly up to 
13 times, mentioning the sentence from the text 12 times and once for making conclusion.

Before reading the texts, students had to preview the texts. There are three options of previewing strategies: (1) answering some questions from reading text; (2) thinking about the topic, and (3) predicting the content and examining vocabulary in context. Based on the data, all students used all the previewing strategies. Based on interview transcribed, students preferred not to do the previewing strategy. They would like to read the texts directly and answer the questions. Besides, they preferred to use previewing strategy, from thinking about the topic to other strategies like predicting the content and examining vocabulary in context.

\subsubsection{Strategies to Find the Word Refers to}

The strategies used by students to find detail information were varied. They used more than one strategy for different type of questions. There were different types of questions in finding detail information such as finding the word refers to, finding synonym, and giving definition.

Strategies used by students in finding the word refers to were referring to subject in previous sentence, referring to previous sentence, mentioning incomplete word, referring to the word after and combining the sentences. There are three questions of references. Question number one: "What does the word "they" in the second paragraph line 4 refer to?" was taken from reading text 1 question number 2. Question number two: "What does the word "it" in line 4 refer to?" was taken from reading text 2 number 2. Question number three: What does the word "they" in line 16 refer to?" was taken from reading text 2 number 5 .

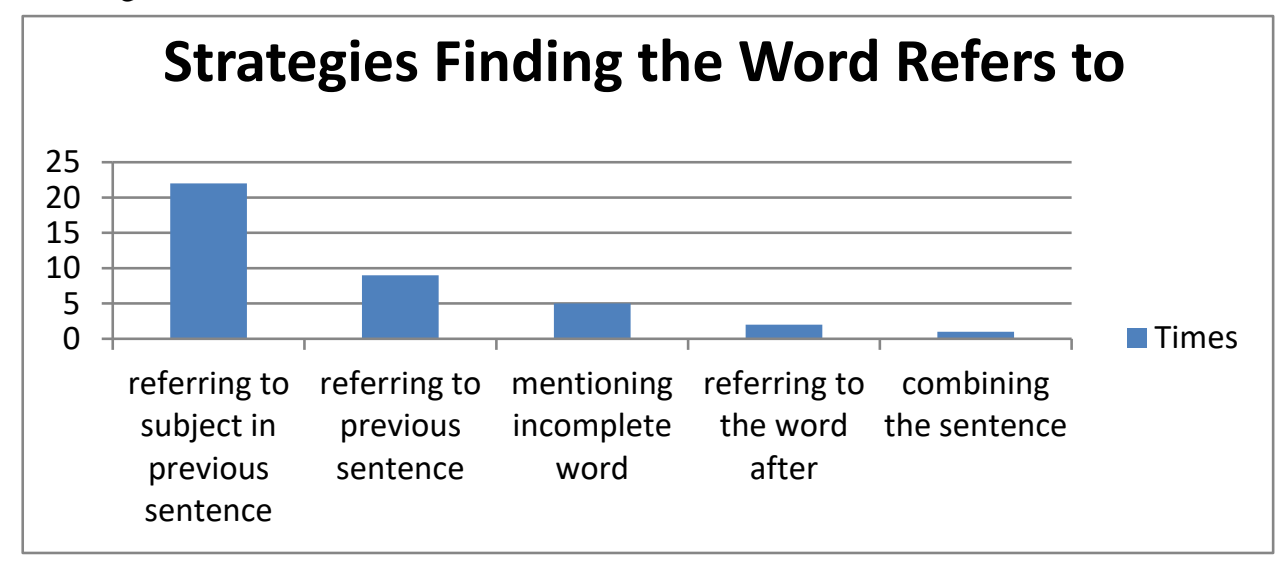

Figure 3. Strategies finding the word refers to

As we can see in the above graph, students used the phrase referring to previous sentence 9 times, referring to subject in previous sentence 22 times, and mentioning incomplete word 5 times, while the phrase referring to the word after was used twice and combining the sentences was used only once.

\subsubsection{Strategies of Synonym}

Strategies used by students in finding synonym were namely choosing the right word from the provided option, making definition, mentioning other words that was out of text and mentioning other synonyms which were not mentioned in the text. There were two questions about synonym. Question number one was taken from reading text 1 number 2 . The word "purchase" in the first paragraph, has similar meaning with: a. borrow b. buy c. sell." Question number two was taken from reading text 2 number 4 . The word "emphasize" in line 10 is closest in meaning to ------- in paragraph two.

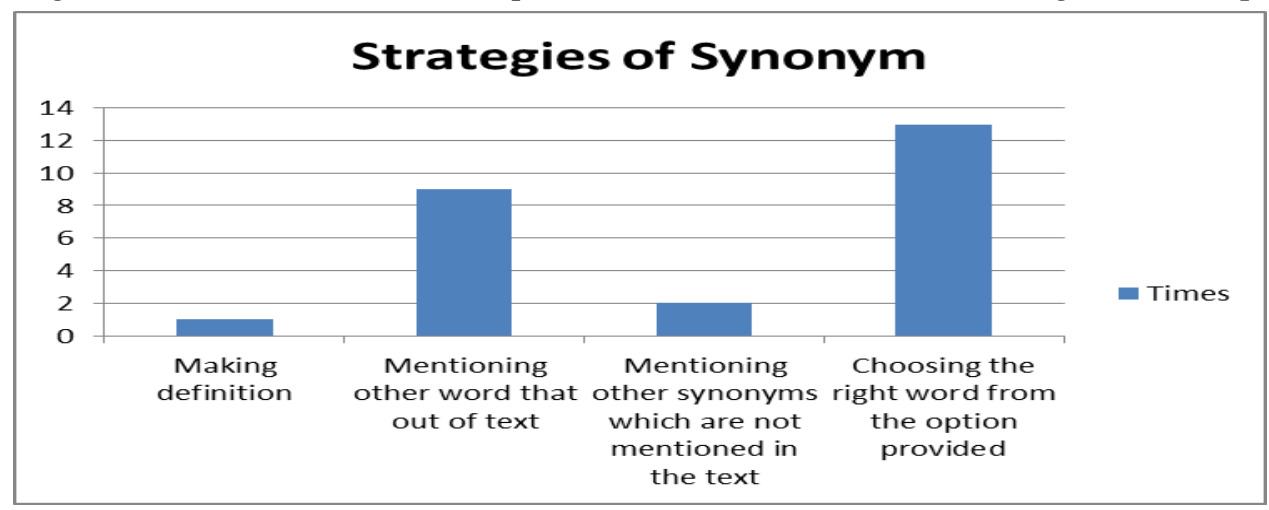

Figure 4. Strategies of synonym 
Based on the data, students used more than one strategy to find synonym in reading text. The students used strategies: choosing the right word from the provided option 13 times, mentioning other word that out of context 9 times, twice for mentioning other synonyms which are not mentioned in the text, and once for making definition.

\subsubsection{Strategies to Find Definition}

Students used more than one strategy to find definition. The strategies are (1) mentioning the same word without mentioning its definition, (2) finding the answer from dictionary, and (3) finding the synonym of the word. The question was taken from reading text 2 number 5 . The question: "Product differentiation" means the product is - “6

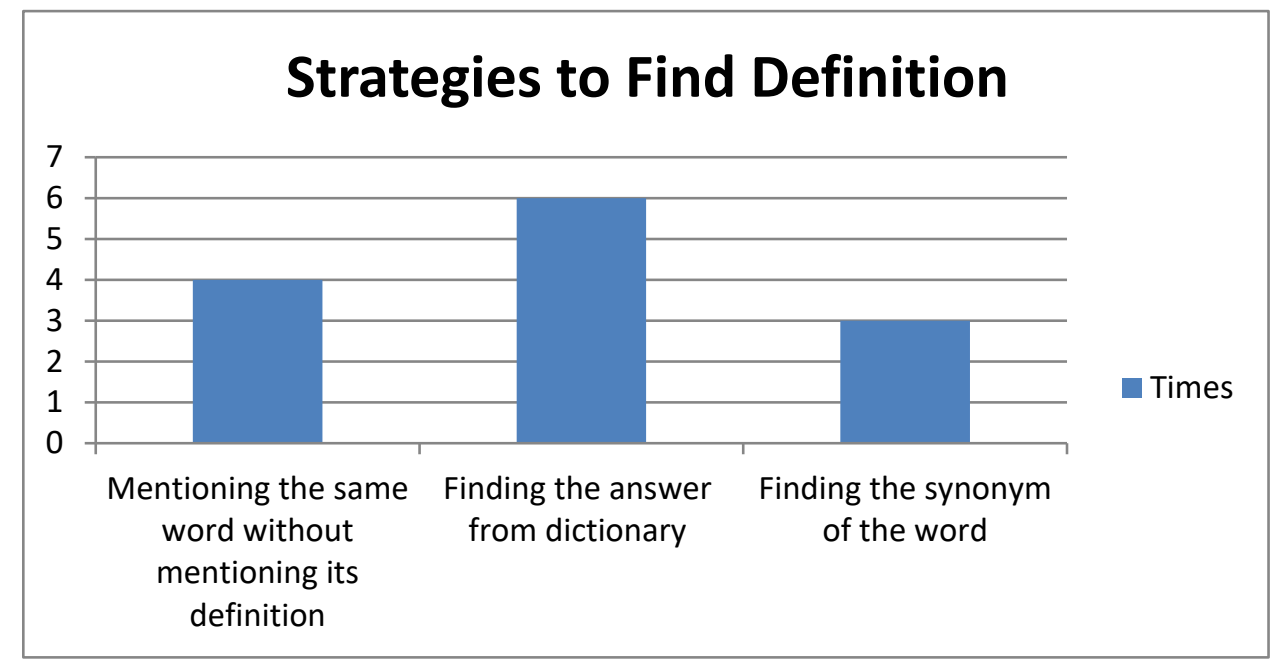

Figure 5. Strategies to Find Definition

From figure 5, we can see that students used strategy mentioning the same word without mentioning its definition for 4 times, finding the answer from dictionary for 6 times, and finding the synonym for 3 times.

\subsection{Previewing Strategies}

Based on activities before reading the text, the data showed that 8 students preferred answering questions directly without previewing the text, 2 students preferred answering some questions or having previewing strategy before reading the text, and 3 students preferred not answering the questions.

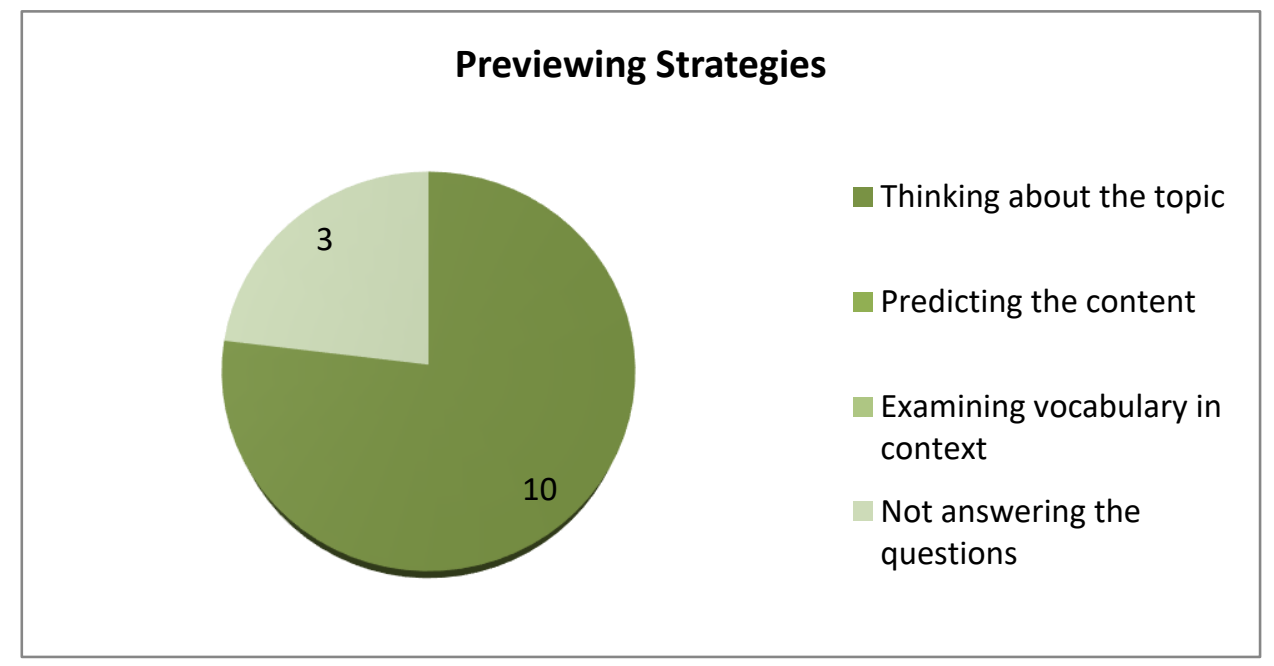

Figure 6. Previewing Strategies

Figure 6 showed that 10 students preferred thinking about the topic before reading the text, 3 students preferred not answering the questions, and none of students preferred predicting the content and examining vocabulary in context. 


\subsection{Accuracy/Inaccuracy to Answer Questions}

In this section, accurate and inaccurate answer made by students in answering questions from reading texts is presented.
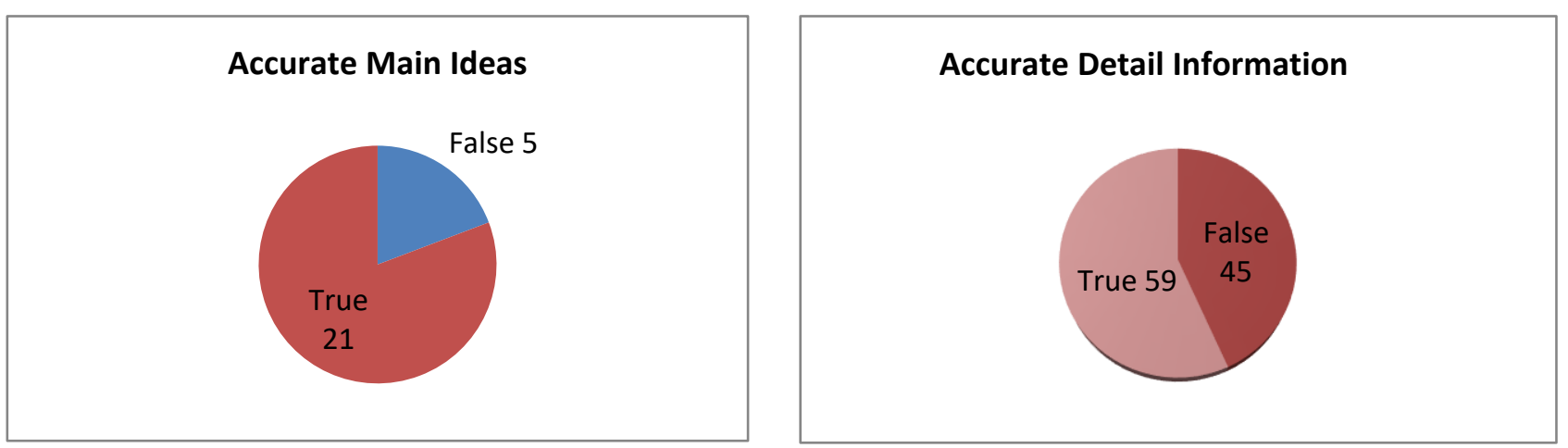

Figure 7. Accurate Main Ideas and Detail Information

The chart shows accurate and inaccurate answers made by students in answering questions about main ideas. From 13 students and 26 answers, 21 times students answered the questions accurately and 5 times students answered inaccurately. Then, the next chart shows accurate and inaccurate answer made by students in answering detail questions, in which 59 times student answered the questions of finding detail information accurately and 45 times student answered the questions of finding detail information inaccurately.

Based on the finding presented above, the strategies to find main ideas are varied. Some of the students tried to find the main idea from the first, the second, and the last sentences of the paragraph. There were also varied strategies to find out the detail information.

\section{Conclusion}

Strategies used by students in finding main ideas and detail information are varied. Students frequently used more than one strategy in finding main ideas and detail information. The strategy that often used by students in finding main idea was taking from the first sentence in paragraph. The strategy that frequently used by students in finding detail information were referring to subject in previous sentence, choosing the right word from the provided option, finding the answer from dictionary and mentioning the place and time directly. All students did previewing strategy before answering the question but in an interview they preferred answering questions in reading text directly without taking previewing strategy.

There are several suggestions for teacher especially English teacher. They are advised to encourage students to practice answering questions from reading text. They ought to explain some previewing strategies and make use of it by practicing the strategies before reading the text. Strategies in finding main ideas and answering detail questions should be explored more to identify problems and solutions in reading comprehension. With respect to Think-Aloud Protocol an interview with students should be conducted deeper to identify some reasons of using certain strategies in finding main ideas and detail questions.

\section{Acknowledgements}

The researchers thank to the Director and Board of Research and Community Service of ABFI Perbanas Institute Jakarta and Politeknik AKA Bogor-Indonesia, industries, and all stakeholders who have given good support.

\section{References}

Alderson, J. C. (2000). Assessing Reading. United Kingdom: Cambridge University Press. https://doi.org/10.1017/CBO9780511732935

Anderson, N. J. (2006). Increasing metacognitive awareness in the L2 classroom by using think aloud protocols and other verbal report formats. In Rebecca L. Oxford (Eds.). Journal of Language Learning Strategies Around the World: Cross Cultural Perspectives, 13, 3-18.

Cook, R., Pedretti, M., \& Helen, S. (2009). Total Business 1 Student's Book. United Kingdom, Summertown Publishing Ltd.

Dhillon, B., Herman, H., \& Syafryadin, S. (2020). The Effect of Skimming Method to Improve Students' Ability in Reading Comprehension on Narrative Text. Linguists: Journal of Linguistics and Language Teaching, 6(1), 77-88.

Fellag, L. R. (2006). College Reading 2. Boston, New York: Houghton Mifflin Company. 
Gonzales, M. D. R. (2017). Using Reading Strategies to Help Students Improve Their Reading Learning Process (thesis). Bogota D.C, University of Lasalle.

Lumbatobing, S. R. A. H., Pardede, H., \& Herman. (2020). The Effect of Herringbone Technique on the Students' Ability in Reading Comprehension on Recount Text. Journal of English Educational Study, 3(2), 1-10, November 2020, E-ISSN: 2655-0776. https://doi.org/10.31932/jees.v3i2.656

Nunan, D., \& Bailey, K. M. (1993). Research methodology in language learning (2nd ed.). New York: Cambridge University Press.

Prichard, C., \& Andrew, A. (2016). Readers Previewing Strategies Using Eye Tracking. An International Online Journal: The Reading Matrix, 16(2).

Richards, J., \& Richard, S. (2002). Longman Dictionary of Language Teaching and Applied Linguistics. Endinburgh: Larson Education Limited.

Sirait, M. F., Hutauruk, B. S., \& Herman. (2020). The Effect of Using Speed Reading Technique to the Students' Ability in Comprehending a Text. Cetta: Jurnal Ilmu Pendidikan, 3(3), 485-498.

Souhila, R. (2013). The Use of Reading Strategies In Improving Reading Comprehension (dissertation). Algeria, University Kasdi Merbah Quargia.

Tenaha, O'reily, Best, R., \& Danielle, S. M. (2004). Self-explanation Reading Training: Effects for Low Knowledge Readers. Proceeding of the Annual Meeting of the Cognitive Science Society, 26(26).

William, A. D. (2006). Using a Previewing Strategy to Enhance Reading Comprehension of Secondary Student (dissertation). Knoxville: University of Tennessee.

Williams, J., \& Andrew, C. (2002). The Map: A Beginner's Guide to Doing Research in Translation Studies. Manchester, UK: St. Jerome Publishing

\section{Copyrights}

Copyright for this article is retained by the author(s), with first publication rights granted to the journal.

This is an open-access article distributed under the terms and conditions of the Creative Commons Attribution license (http://creativecommons.org/licenses/by/4.0/). 